\title{
PELATIHAN KETERAMPILAN LAS LOGAM DAN CHROME LOGAM KEPADA MAHASISWA PESERTA KKN PPM UNTUK PENGEMBANGAN WIRAUSAHA KERAJINAN LOGAM SEBAGAI KOMODITAS KHAS DESA SUNGAI MERANTI KECAMATAN PINGGIR KABUPATEN BENGKALIS
}

\author{
Sunaryo ${ }^{1)}$, Yuhelson ${ }^{2)}$, Ari Andriyas Puji ${ }^{3)}$ \\ 1) Universitas Muhammadiyah Riau \\ Email : sunaryo@umri.ac.id
}

\begin{abstract}
ABSTRAK
Dalam kegiatan kuliah kerja nyata $(\mathrm{KKN})$ dalam bentuk pembelajaran pemberdayaan masyarakat (PPM) ini, akan dilakukan pemberdayaan secara generik, yaitu dimulai dengan pola pencitraan karang taruna menjadi kelompok produktif yang berguna dalam mendukung munculnya wirausaha baru yang kreatif, peningkatan kecakapan hidup (life skill), dan pola pemasaran yang bersifat kolaboratif dengan memanfaatkan keunggulan daerah sebagai kota wisata. KKN PPM pemuda karang taruna melalui proses transfer keterampilan untuk las logam dan chrome logam untuk pengembangan wirausaha kerajinan logam sebagai komoditas khas desa sungai meranti kecamatan pinggir kabupaten bengkalis. Metode kegiatan program KKNPPM ini adalah metode workshop dalam bentuk pelatihan dan pendampingan mahasiswa peserta KKN PPM secara intensif sampai menghasilkan produk berupa kerajinan logam souvenir dan hiasan yang menjadi komoditas produk desa sungai meranti kecamatan pinggir kabupaten bengkalis, serta membantu akses pemasaran yang bersifat kontinyu. Sekitar $60 \%$ (12 dari 20 orang peserta ) mahasiswa mendapatkan nilai keberhasilan lebih dari 85 yang berarti telah mengusai sistem pengelasan dan chrome dengan baik secara teori maupun praktek. $40 \%$ yang lain dari peserta pelatihan dalam kondisi cukup menguasai pengelasan \& chrome tersebut. Sebagian besar Para peserta pelatihan telah memiliki keterampilan untuk bisa menstranfer keterampilannya ke remaja karang taruna desa sungai meranti yang akan di jadikan pembinaannya dalam pelaksanaan KKN PPM.
\end{abstract}

Kata kunci: pemberdayaan, transfer keterampilan, mahasiswa, karangtaruna

\section{ABSTRACT}

In the real work lecture activity in the form of community empowerment learning, generic empowerment will be carried out, that is, it starts with the pattern of imaging young people into productive groups that are useful in supporting the emergence of new creative entrepreneurs, increasing life skills (life skills), and collaborative marketing patterns that take advantage of regional advantages as a tourist city real work lecture activity youth cadets through the process of transferring skills for metal welding and metal chrome for the development of metal craft entrepreneurs as a commodity typical of the meranti river village sub-district of Bengkulu district. The method of real work lecture activity program activities is a workshop method in the form of training and mentoring of students participating in the real work lecture activity intensively to produce products in the form of souvenirs and decoration metal handicrafts which are commodity products of meranti river villages in the sub-districts of Bengkulu district, as well as helping continuous marketing access. About $60 \%$ (12 out of 20 participants) students get a success score of more than 85 which means they have mastered the welding and chrome systems both in theory and practice. The other $40 \%$ of the training participants were in a sufficient condition to master the welding \& chrome. Most of the trainees already have the skills to be able to transfer their skills to the youth of the meranti river Karang Taruna youth which will be their guidance in the implementation of real work lecture activity.

Key word : empowerment, skills transfer, students, karangtaruna 


\section{PENDAHULUAN}

Bidang usaha produktif yang dipilih dalam kegiatan KKN-PPM ini adalah bidang las logam dan chroom logam karena sangat potensial untuk langsung dijadikan wirausaha baru. bidang las logam dan chroom logam adalah usaha yang masih sangat minim pesaing di Indonesia. Kerajinan seni las dan choom yang dibuat untuk souvenir, cinderamata, aksesoris, trophy, dan hiasan interior. Usaha kerajinan bidang las logam dan chroom logam saat ini mengalami perkembangan yang cukup signifikan. Pemasaran produk kerajinan tersebut tidak hanya merambah kota-kota besar di Indonesia. Kondisi tersebut membuat sebagian besar pengrajin bidang las logam dan chroom logam berlomba-lomba menghasilkan kreasi produk yang menarik, agar bisa dilirik customer lokal maupun mancanegara. Salah satu contoh perubahan fisik ketika material dilapis dengan nikel adalah bertambahnya daya tahan material tersebut terhadap korosi, serta bertambahnya kapasitas konduktifitasnya. Adapun dalam sifat mekanik, terjadi perubahan kekuatan tarik maupun tekan dari suatu material sesudah mengalami pelapisan dibandingkan sebelumnya.

Dalam kegiatan kuliah kerja nyata $(\mathrm{KKN})$ dalam bentuk pembelajaran pemberdayaan masyarakat (PPM) ini, akan dilakukan pemberdayaan secara generik, yaitu dimulai dengan pola pencitraan karang taruna menjadi kelompok produktif yang berguna dalam mendukung munculnya wirausaha baru yang kreatif, peningkatan kecakapan hidup (life skill), dan pola pemasaran yang bersifat kolaboratif dengan memanfaatkan keunggulan daerah sebagai kota wisata.

1. Meningkatkan keterampilan mahasiswa sebagai sasaran antara yang strategis dalam mendesain dan membuat produk kerajinan dari hasil keterampilan logam sehingga menghasilkan komoditas yang dapat dipasarkan melalui kegiatan workshop dan pendampingan.

2. Melibatkan mahasiswa dalam peningkatan keterampilan pemuda usia produktif melalui lembaga karang taruna sebagai sasaran utama yang strategis dalam mendesain dan membuat kerajinan las logam dan chrome logam dengan menggunakan pengelasan dan proses chrome sebagai produk unggulan kota budaya melayu melalui kegiatan workshop dan pendampingan.

3. Membangun jaringan kerja dalam bentuk kelompok produksi pemuda dan membuka akses pemasaran melalui kemitraan dengan karang taruna dan perguruan tinggi.

4. Memberikan pelatihan pada pihak pemuda lain yang tidak tergabung dalam karang taruna tentang pemanfaatan las logam dan chrome logam sekaligus pendampingan promosi pemasaran produknya.

5. Mengembangkan pola pemberdayaan kolaboratif melalui pendampingan dalam transfer keterampilan, dan akses pemasaran yang lebih luas.

\section{TINJAUAN PUSTAKA}

\section{a. Pengelasan}

Pada pengelasan listrik berkas elektron, sambungan terjadi karena benda kerja di hujani oleh berkas elektron berkecepatan sangat tinggi, akibat nya pinggiran benda yang akan dilas mencair atau dapat dikatakan oleh adanya penetrasi dari electron. Biasanya tidak digunakan filler dan proses ini baik digunakan tidak saja untuk logam biasa, tetapi juga digunakan untuk logam keras yang tahan api, termasuk logam-logam yang sulit dilas menggunakan pengelasan biasa. Untuk supaya lebih jelas, perhatikan gambar berikut ini. Senapan elektron berada dalam ruang hampa yang di atur sedemikian rupa, sehingga 
dapat ditarik ke atas maupun ke bawah ataupun bergerak dalam bidang datar. Ruang hampa biasanya mencapai tekanan dimana serangkaian berkas dipasangkan dan di arah kan secara terpusat dan fixed (stasioner), baru kemudian benda kerja nya yang bergerak. Sangkin panas nya berkas elektron ini, sehingga mampu membuat wolfram menjadi uap, bahkan bahan-bahan dengan titik didih yang tinggin sekali pun mampu dijadikan uap.Proses pengelasan listrik berkas elektron ini dapat dikendalikan secara numerik khusus nya untuk komponen elektronika dan tercatat mempunyai kecepatan pengelasan sedemikian tinggi (misal: untuk Al-alloy 2024 T-4 setebal $12 \mathrm{~mm}$, kecepatan pengelasan nya $=800 \mathrm{~mm} / \mathrm{menit}$ ), sehingga komposisi metalurgi ke-2 logam induk tidak sempat terpengaruh.Berkas elektron terbentuk di dalam ruang hampa, lalu mengalir melintasi lubang khusus dan menembus gas Argon atau Helium, lalu mengenai benda kerja (logam induk).

\section{b. Proses chrome}

Selain nikel maka pelapisan khrom banyak dilaksanakan untuk mendapatkan permukaan yang menarik. Karena sifat khas khrom yang sangat tahan karat maka pelapisan khrom mempunyai kelebihaan tersendiri bila dibandingkan dengan pelapisan lainnya.

Selain sifat dekoratif dan atraktif dari pelapisan khrom, keuntungan lain dari pelapisan khrom adalah dapat dicapainya hasil pelapisan yang keras.

Sumber logam khrom didapat dari asam khrom, tapi dalam perdagangan yang tersedia adalah khrom oksida $\left(\mathrm{Cr}_{3}\right)$ sehingga terdapatnya asam khrom adalah pada waktu khrom oksida bercampur dengan air

$$
\mathrm{Cr} \mathrm{O}_{3}+\mathrm{H}_{2} \mathrm{O} \longrightarrow \mathrm{H}_{2} \mathrm{Cr} \mathrm{O}_{4}
$$

Larutan elektrolit yang digunakan dalam pelapisan khrom adalah campuran antara asam khrom dengan asam sulfat. Perbandingan antara asam khrom dan asam sulfat adalah $100: 1$. Fungsi asam sulfat dalam larutan adalah sebagai katalisator.

Komposisi larutan tiap liter air dapat dilihat dibawah ini :

$$
\begin{array}{ccc}
\mathrm{I} & \mathrm{II} & \mathrm{III} \\
-\mathrm{Cr} \mathrm{O}_{3}: 225-250 \mathrm{gr} / 1 & -360-400 \mathrm{gr} / 1 & -270-300 \mathrm{gr} / 1 \\
-\mathrm{H}_{2} \mathrm{SO}_{4}: 2,25-2,50 \mathrm{gr} / 1 & -3,60-4,00 \mathrm{gr} / 1 & -2,70-3,00 \mathrm{gr} / 1
\end{array}
$$

Kondisi operasi :

$$
\begin{array}{ll}
\text { - Suhu } & : 45-55^{\circ} \mathrm{C} \\
\text { - Rapat arus } & : 5-30 \mathrm{~A} / \mathrm{dm}^{2}
\end{array}
$$

Rapat arus yang digunakan selama pelapisan dapat meningkat sebanding dengan meningkatnya suhu. Hal ini dapat dijelaskan sebagai berikut :

1. Bila rapat arus meningkat maka suhu juga harus meningkat

2. Bila rapat arus meningkat maka kecepatan pelapisan juga meningkat

3. Bila rapat arus meningkat dibutuhkan sumber tegangan lebih tinggi

4. Bila lapisan mengkilap berarti lapisan juga keras

Anoda yang digunakan dalam pelapisan khrom bersifat tak larut dan ada beberapa jenis: 1. Timah hitam 
2. Paduan timah hitam-timah putih.

3. Paduan timah hitam -antimon

4. Besi

\section{METODE PELAKSANAAN}

\section{a. Persiapan dan Pembekalan}

Persiapan dan pembekalan dilakukan sebelum mahasiswa KKN PPM diterjunkan kelokasi desa sungai meranti terlebih dahulu diberi pelatihan dan pendampingan yang diuraikan sebagai berikut :

\section{Materi persiapan dan pembekalan KKN-PPM}

Materi persiapan dan pembekalan KKN PPM terdiri dari :

1) Sejarah dan Filosofi KKN PPM

2) Materi ini menjelaskan tentang arti, tujuan, sasaran, dan manfaat dari KKN PPM

3) Masalah, identifikasi masalah dan pemecahan masalah

4) Menggambarkn atau memaparkan kondisi dan situasi permasalahan yang akan di jadikan tempat kegiatan KKN

5) Rencana Program pokok dan Program Pendamping

6) Memaparkan rencana program pokok dan program pendamping selama kegiatan berlangsung sebulan penuh.

7) Deskripsi tugas dan tata tertib mahasiswa peserta KKN PPM

8) Membagi tugas dan tata tertib KKN PPM yang mengacu pada ketentuan KKN PPM UMRI mekanisme pembuatan laporan

9) memaparkan bagaimana cara membuat laporan yang benar sesuai standar dari universitas.

Selama proses penyampaian materi pembekalan kepada mahasiswa peserta KKN PPM yang mengacu kepada prosedur yang telah baku di UMRI.

\section{b. Pelaksanaan}

\section{Mekanisme pelaksanaan kegiatan KKN-PPM}

Metode kegiatan program pokok KKN-PPM ini adalah metode workshop dalam bentuk pelatihan dan pendampingan secara intensif sampai menghasilkan produk berupa kerajinan logam yang menjadi komoditas produk kota wisata budaya melayu Bengkalis, serta membantu akses pemasaran yang bersifat kontinyu. Kegiatan pelatihan dlaksanakan selama 70 JKEM dengan struktur program sebagai berikut:

Tabel 1. Struktur Program Pelatihan Perancangan Produk Kerajinan Logam dan chrome bagi Pemuda Karang Taruna dengan Mahasiswa peserta KKN-PPM

\begin{tabular}{|l|l|l|l|c|}
\hline No & \multicolumn{1}{|c|}{ Materi Pelatihan } & \multicolumn{1}{|c|}{ Jenis Kegiatan } & $\begin{array}{c}\text { Jumlah Jam } \\
\text { Efektif }\end{array}$ & $\begin{array}{c}\text { Jumlah } \\
\text { Pemuda }\end{array}$ \\
\hline Hari 1 & $\begin{array}{l}\text { Pengenalan Desain } \\
\text { kerajinan logam }\end{array}$ & $\begin{array}{l}\text { Presentasi dan Focus Group } \\
\text { Discusion (FGD) }\end{array}$ & 4 JKEM & 20 \\
\hline 2 & $\begin{array}{l}\text { Teknik pemilihan bahan } \\
\text { logam }\end{array}$ & Teori dan Praktek & 4 JKEM & 20 \\
\hline 3 & $\begin{array}{l}\text { Teknik pengelasan logam } \\
\text { untuk produk kerajinan }\end{array}$ & Teori dan Praktek & 10 JKEM & 20 \\
\hline
\end{tabular}




\begin{tabular}{|l|l|l|l|c|}
\hline 4 & $\begin{array}{l}\text { Pembuatan kerajinan } \\
\text { berbasis bahan logam }\end{array}$ & Teori dan Praktek & 20 \\
\hline Hai 2 & $\begin{array}{l}\text { Pengenalan Desain } \\
\text { kerajinan chrome Logam }\end{array}$ & $\begin{array}{l}\text { Presentasi dan Focus Group } \\
\text { Discusion (FGD) }\end{array}$ & 4 JKEM & 20 \\
\hline 2 & $\begin{array}{l}\text { Teknik pemilihan bahan } \\
\text { chrome }\end{array}$ & Teori dan Praktek & 4 JKEM & 20 \\
\hline 3 & $\begin{array}{l}\text { Teknik proses chrome } \\
\text { logam untuk produk } \\
\text { kerajinan }\end{array}$ & Teori dan Praktek & 10 JKEM & 20 \\
\hline 4 & $\begin{array}{l}\text { Pembuatan kerajinan } \\
\text { berbasis bahan logam } \\
\text { chrome }\end{array}$ & Teori dan Praktek & 12 JKEM & 20 \\
\hline Hari 3 & $\begin{array}{l}\text { Pelatihan manajemen } \\
\text { keuangan dan pencarian } \\
\text { modal }\end{array}$ & $\begin{array}{l}\text { Praktek dan Focus Group } \\
\text { Discusion (FGD) }\end{array}$ & 3 JKEM & 20 \\
\hline 2 & $\begin{array}{l}\text { Pelatihan pemasaran } \\
\text { produk kerajinan logam } \\
\text { dan chrome }\end{array}$ & $\begin{array}{l}\text { Praktek dan Focus Group } \\
\text { Discusion (FGD) }\end{array}$ & 4 JKEM & 20 \\
\hline 3 & $\begin{array}{l}\text { Strategi pengelolaan } \\
\text { usaha kecil menengah }\end{array}$ & Teori dan Praktek & 3 JKEM & 20 \\
\hline & \multicolumn{2}{|l|}{ Total } & JKEM & \\
\hline
\end{tabular}

\section{c. Persiapan dan Pembekalan}

Persiapan dan pembekalan dilakukan sebelum mahasiswa KKN PPM diterjunkan kelokasi desa sungai meranti terlebih dahulu diberi pelatihan dan pendampingan yang diuraikan sebagai berikut :

\section{Materi persiapan dan pembekalan KKN-PPM}

Materi persiapan dan pembekalan KKN PPM terdiri dari :

1. Sejarah dan Filosofi KKN PPM

Materi ini menjelaskan tentang arti, tujuan, sasaran, dan manfaat dari KKN PPM )

2. Masalah, identifikasi masalah dan pemecahan masalah

Menggambarkn atau memaparkan kondisi dan situasi permasalahan yang akan di jadikan tempat kegiatan KKN

3. Rencana Program pokok dan Program Pendamping

Memaparkan rencana program pokok dan program pendamping selama kegiatan berlangsung sebulan penuh.

4. Deskripsi tugas dan tata tertib mahasiswa peserta KKN PPM

Membagi tugas dan tata tertib KKN PPM yang mengacu pada ketentuan KKN PPM UMRI

5. Mekanisme pembuatan laporan

memaparkan bagaimana cara membuat laporan yang benar sesuai standar dari universitas.

Selama proses penyampaian materi pembekalan kepada mahasiswa peserta KKN PPM yang mengacu kepada prosedur yang telah baku di UMRI. 


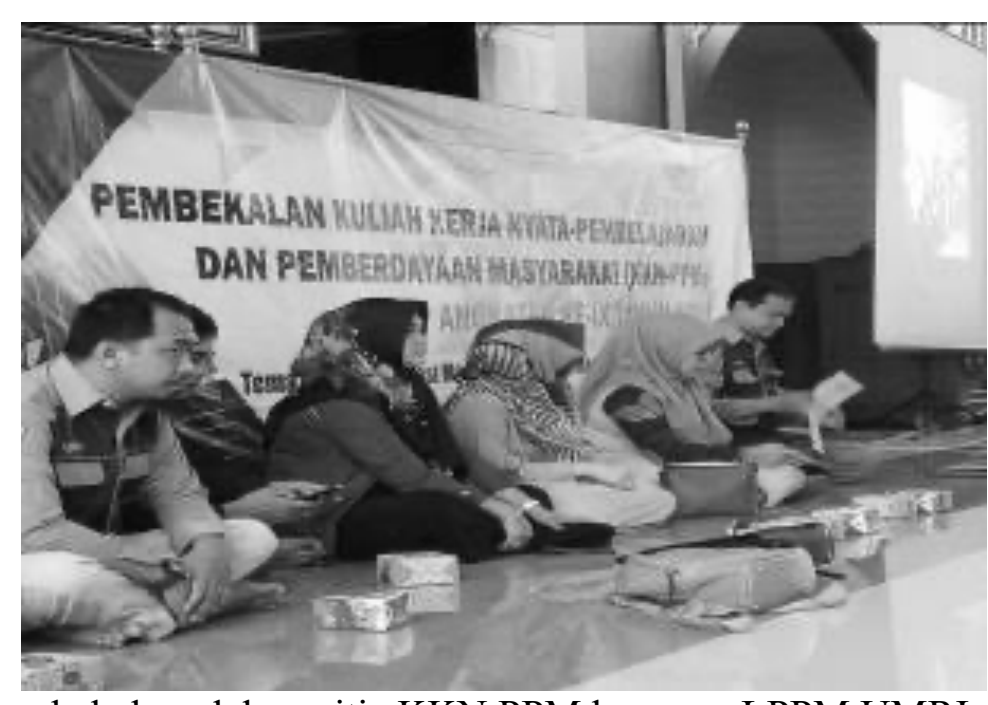

Gambar 1. Pembekalan oleh panitia KKN PPM bersama LPPM UMRI

\section{a. Pelaksanaan}

Mekanisme pelaksanaan kegiatan KKN-PPM

Metode kegiatan program pokok KKN-PPM ini adalah metode workshop dalam bentuk pelatihan dan pendampingan secara intensif sampai menghasilkan produk berupa kerajinan logam yang menjadi komoditas produk kota wisata budaya melayu Bengkalis, serta membantu akses pemasaran yang bersifat kontinyu. Kegiatan pelatihan dlaksanakan selama 70 JKEM dengan struktur program sebagai berikut:

\section{HASIL DAN PEMBAHASAN}

\section{A. Proses pelatihan las listrik}

1. Kesehatan dan keseselamatan kerja

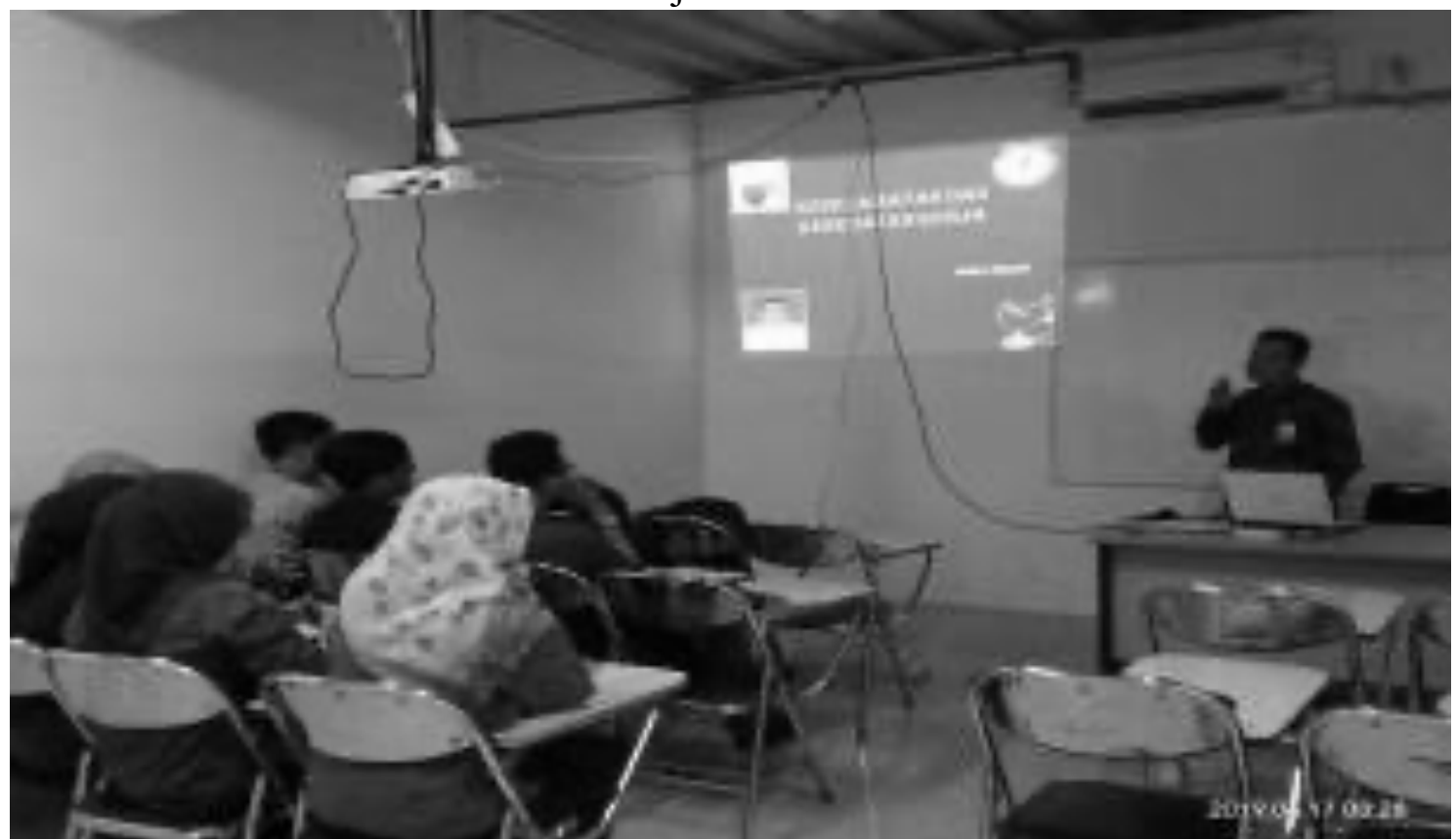

Gambar 2. Penyampaian Materi Kesehatan dan Keselamatan Kerja 
2. Alat ukur

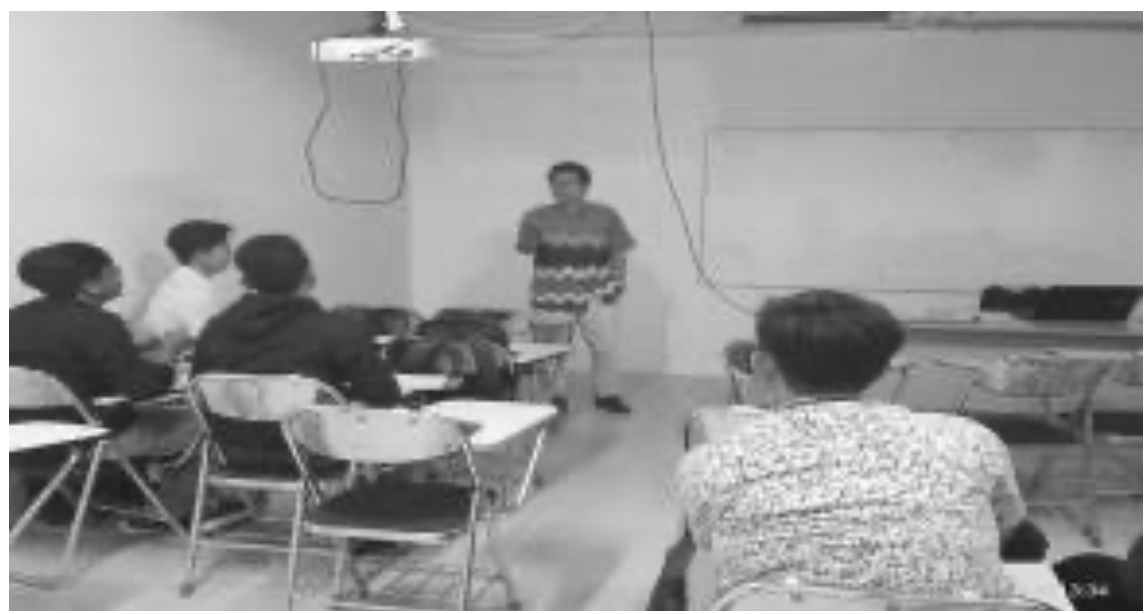

Gambar 3. Penyampaian Materi Alat Ukur

3. Gambar sketsa

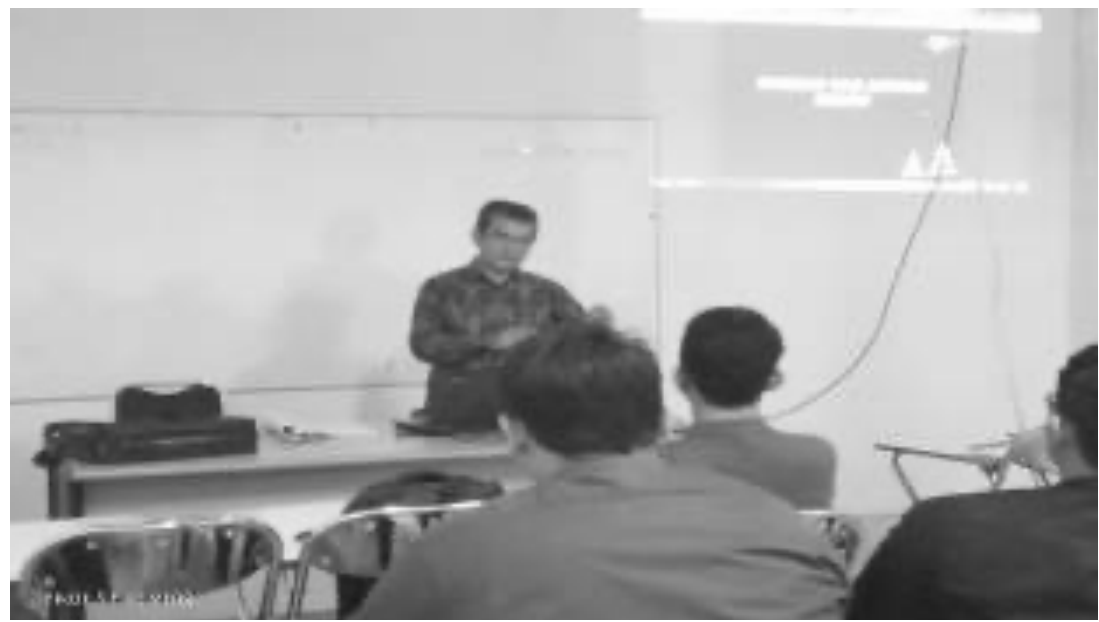

Gambar 4. Penyampaian Materi Sketsa

4. Dasar pengelasan \& pengenalan peralatan las

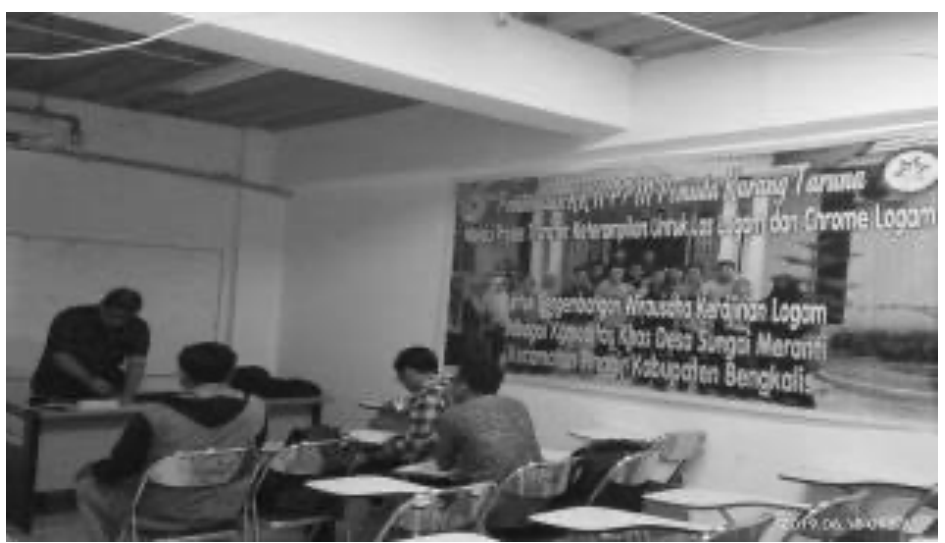

Gambar 5. Dasar pengelasan \& pengenalan peralatan las 
5. Praktek las listrik

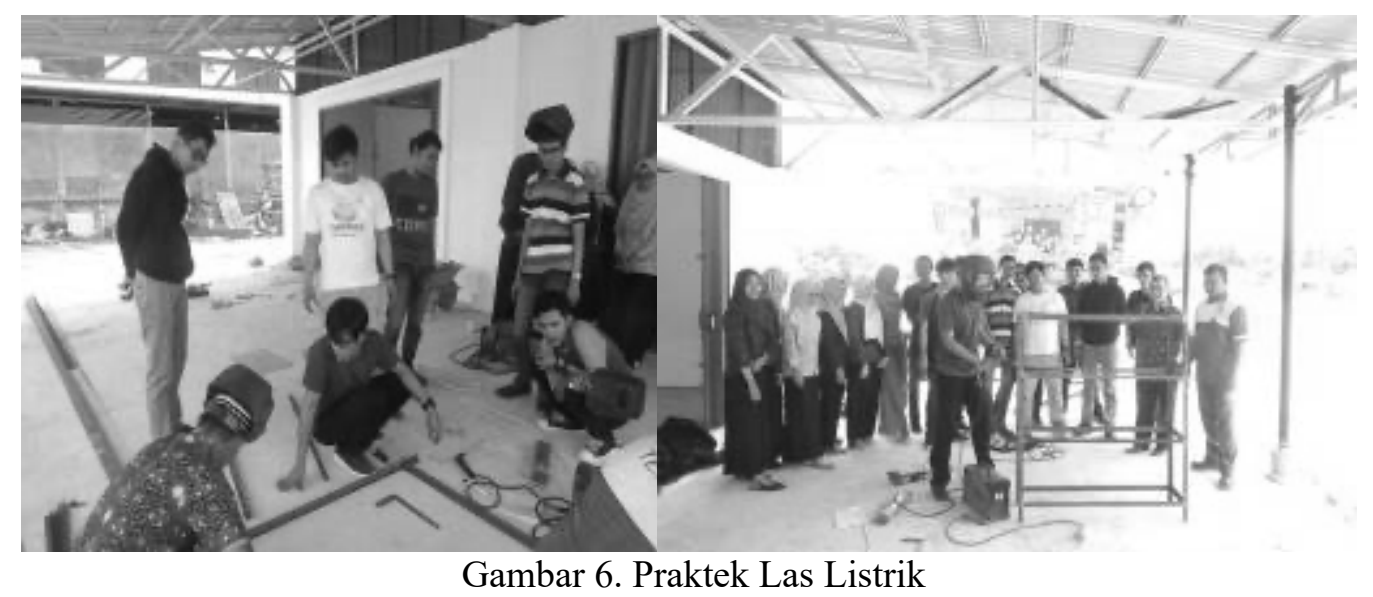

6. Praktek Painting

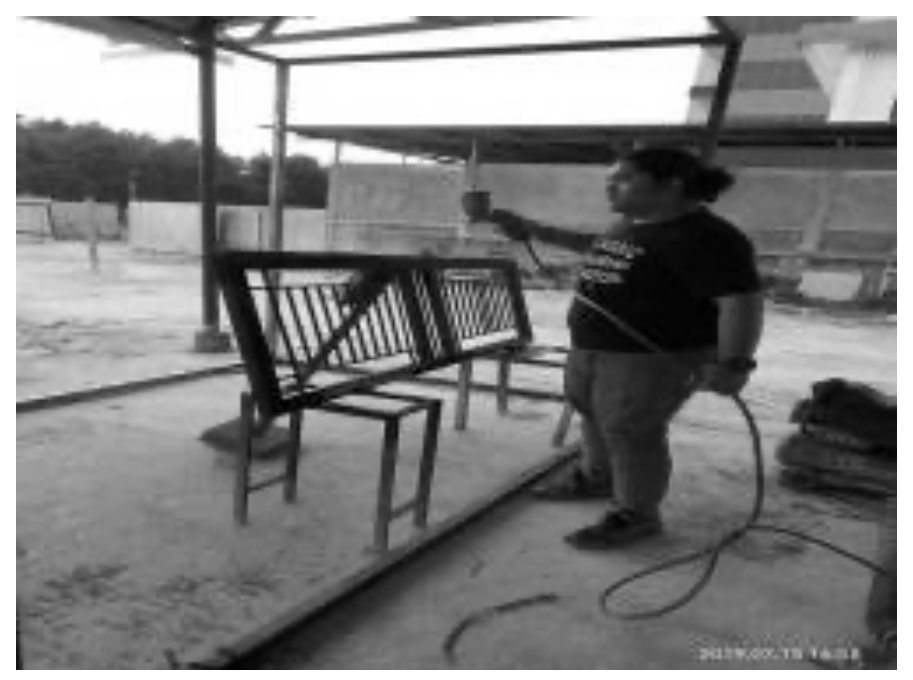

Gambar 7. Praktek Painting

7. Teori dan Teknik Pemasaran Produk kerajinan chrome dan logam

Setelah memahami perencanaan usaha, langkah selanjutnya adalah mempelajari dan melatih bagaimana barang dan jasa yang dihasilkan itu di distribusikan atau di pasarkan. Sesuai dengan definisi pemasaran yaitu kegiatan meneliti kebutuhan dan keinginan konsumen (probe/search), menghasilkan barang dan jasa sesuai dengan kebutuhan dan keinginan konsumen (product), menentukan fingkat harga (price), mempromosikannya agar produk dikenal konsumen (promotion), dan mendistribusikan produk ke tempat konsumen (place), maka tujuan pemasaran adalah bagaimana agar barang dan jasa yang dihasilkan di sukai, dibutuhkan, dan dibeli oleh konsumen

\section{Proses pelatihan Chrome}

Teknik pembuatannya sambung dengan las pada setiap bentuk kemudian dengan bantuan gerinda tangan untuk menghaluskan, bahan 
souvenir logam yang telah dibentuk sesuai keinginan, misalnya patung raja-raja bengkalis,istana ,songket, bentuk manusia, sawit, dan sebagainya dengan kualitas produk mengkilap setelah di chrome. Elektroplating merupakan teknik pelapisan secara elektrodeposisi, yaitu proses pengendapan pelapis logam secara elektrokimia. Cara pelapisan ini memerlukan arus listrik searah (DC). Bila listrik mengalir antara anoda dan katoda, didalam larutan konduktor/larutan elektrolit, maka akan terjadi reaksi kimia pada permukaan logam tersebut. Pada sistem demikian, bila diberi tegangan atau beda potensial, ion-ion bergerak menuju elektroda. Kation bergerak menuju katoda dan anion menuju anoda. Masing-masing mempunyai laju yang khas (konduktivitas ion spesifik). Konduktivitas total larutan tertentu merupakan penjumlahan dan konduktivitas ion individu segenap ion yang dikandungnya. 
9. Tingkat Keberhasilan Mahasiswa Peserta Kkn PPM Dalam Pelatihan Las Dan Chrome

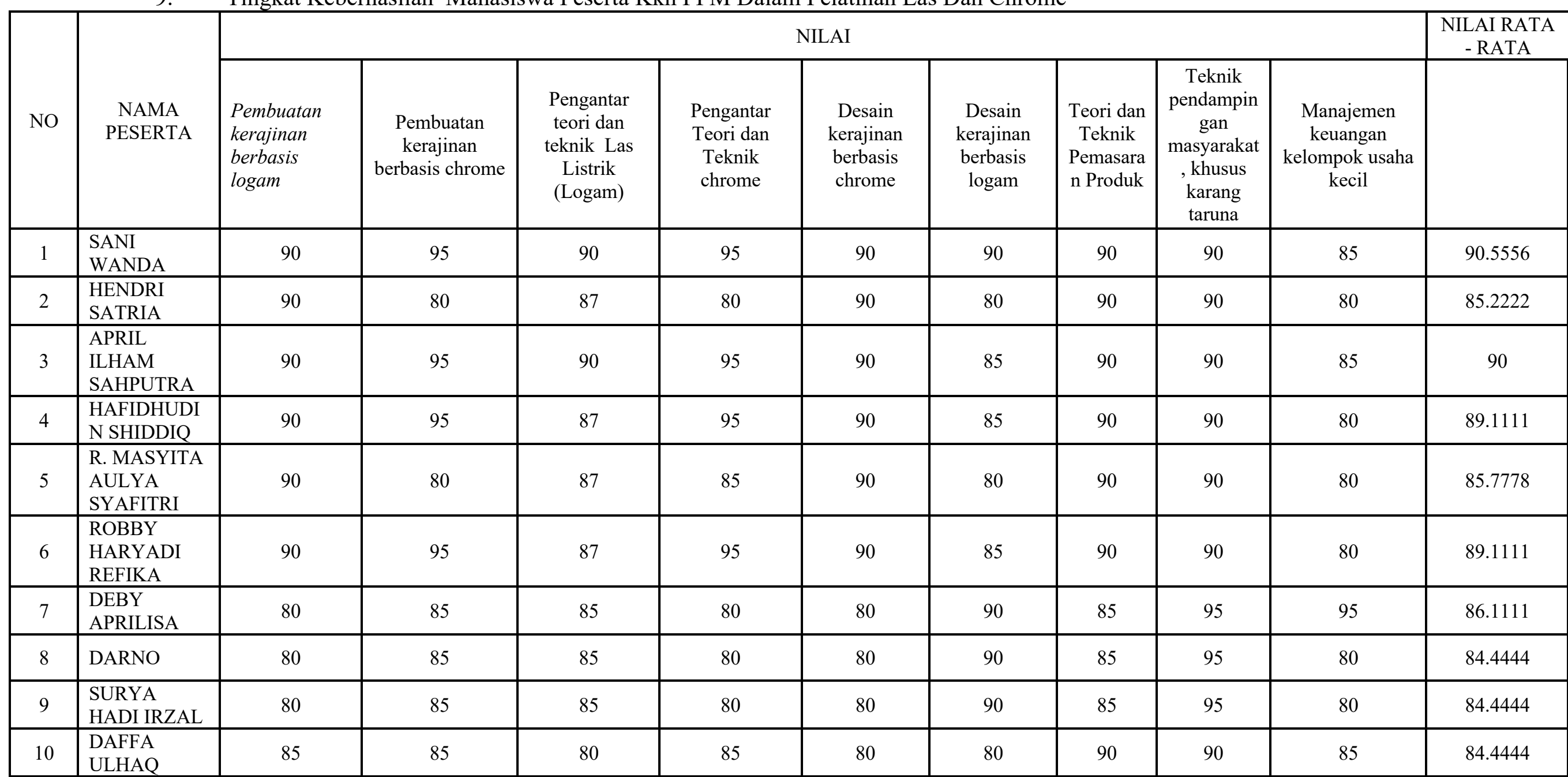


Jurnal Pengabdian Masyarakat Multidisiplin

Volume 3 No. 1 | Oktober 2019 : Hal :53-64

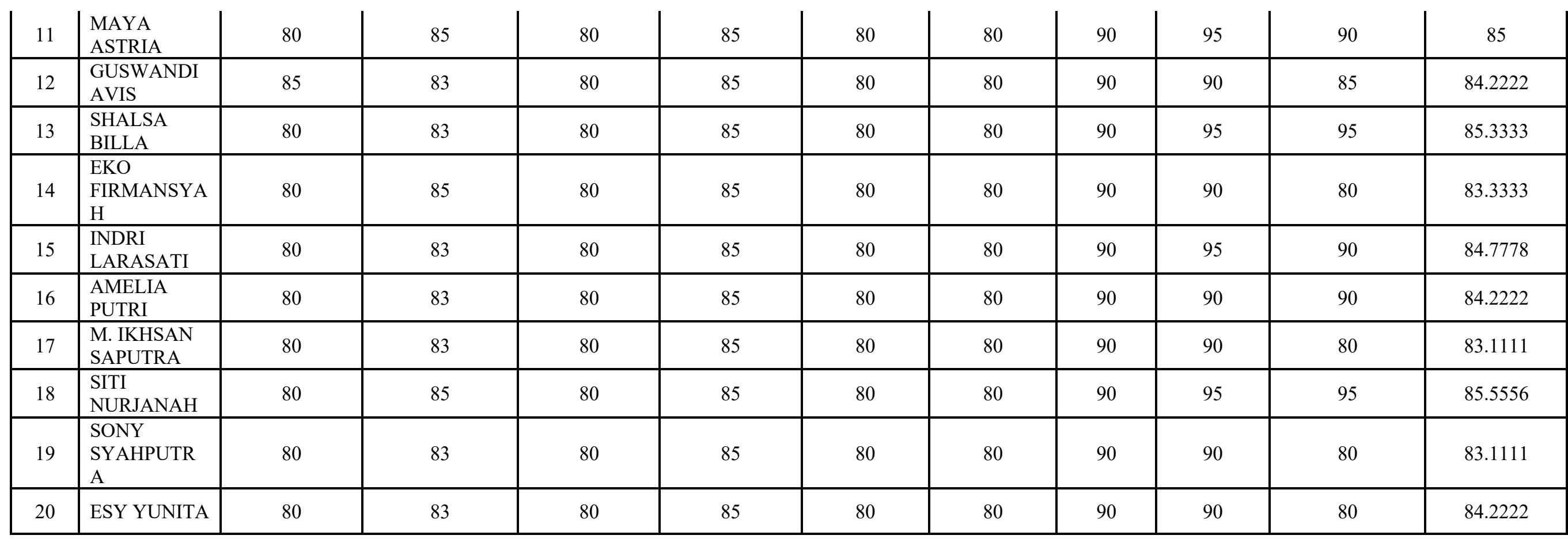


Berdasarkan hasil analisis dapat di jelaskan bahwa Sekitar $45 \%$ (9 dari 20 orang peserta ) mahasiswa mendapatkan nilai keberhasilan lebih dari 85 yang berarti telah mengusai sistem pengelasan dengan baik secar teori maupun praktek. 55\% yang lain dari peserta pelatihan dalam kondisi cukup menguasai pengelasan tersebut. Sekitar 55 $\%$ (11 dari 20 orang peserta ) mahasiswa mendapatkan nilai keberhasilan lebih dari 85 yang berarti telah mengusai pelatihan chrome dengan baik secar teori maupun praktek. $45 \%$ yang lain dari peserta pelatihan dalam kondisi cukup menguasai tentang chrome tersebut. Secara keseluruhan Sekitar $60 \%$ (12 dari 20 orang peserta ) mahasiswa mendapatkan nilai keberhasilan lebih dari 85 yang berarti telah mengusai sistem pengelasan dan chrome dengan baik secara teori maupun praktek. $40 \%$ yang lain dari peserta pelatihan dalam kondisi cukup menguasai pengelasan \& chrome tersebut. Sebagian besar Para peserta pelatihan telah memiliki keterampilan untuk bisa menstranfer keterampilannya ke remaja karangtaruna desa sungai meranti yang akan di jadikan pembinaannya dalam pelaksanaan KKN PPM. Sebagian besar peserta pelatihan memiliki keterampilan berwirausaha sehingga bisa mendapatkan atau menciptakan lapangan kerja. Telah dilaksanakan pembinaan dalam pelatihan terhadap Sebagian besar peserta untuk mendapatkan/menciptakan lapangan pekerjaan khususnya dibidang teknik pengelasan \& chrome.

\section{KESIMPULAN}

Sekitar $60 \%$ (12 dari 20 orang peserta ) mahasiswa mendapatkan nilai keberhasilan lebih dari 85 yang berarti telah mengusai sistem pengelasan dan chrome dengan baik secara teori maupun praktek. $40 \%$ yang lain dari peserta pelatihan dalam kondisi cukup menguasai pengelasan \& chrome tersebut. Sebagian besar Para peserta pelatihan telah memiliki keterampilan untuk bisa menstranfer keterampilannya ke remaja karangtaruna desa sungai meranti yang akan di jadikan pembinaannya dalam pelaksanaan KKN PPM.

\section{DAFTAR PUSTAKA}

[1]. Ahmad Kafrawi Nasution, dkk "studi penyambungan material katup kendaraan menjadi bimetal menggunakan metode friction welding", (Prosiding 2 th Celscitech-UMRI 2017) ISSN: 2541-3023

[2]. BPS, Tingkat pengangguran di Riau, Badan Pusat Statistik Riau,Pressreliase 2018

[3]. Budi istana,dkk. Pelatihan Heat Treatment Sederhana Untuk Siswa Smk SePekanbaru (Jurnal Pengabdian Untuk Mu negeRI) ISSN 2550-0198, November 2017

[4]. Juli Astono dkk, Pemberdayaan Kelompok Pemuda Usia Produktif Melalui Proses Transfer Keterampilan Las Kaca Dan Las Listrik Untuk Pengembangan Wirausaha Kerajinan Kaca Dan Logam Sebagai Komoditas Khas Kota Wisata, , UNY 2013

[5]. Rahmad fahri husein, Kerajinan Souvenir Dari Timah Di Sendangtirto, Berbah, Sleman, UNY 2013

[6]. Sunaryo, dkk, Pelatihan keterampilan las untuk masyarakat usia produktif di kelurahan sukajadi kec. Sukajadi kota pekanbaru" (Jurnal Pengabdian Untuk Mu negeRI)ISSN 2550-0198, Mei 2017

[7]. Yohanes ,dkk "Pengaruh Bentuk Permukaan Forging Sambungan Las Gesek Rotary Terhadap Kekuatan Tarik Baja Mild Steel "(SNTT 4 2016) ISSN : 2339028X 